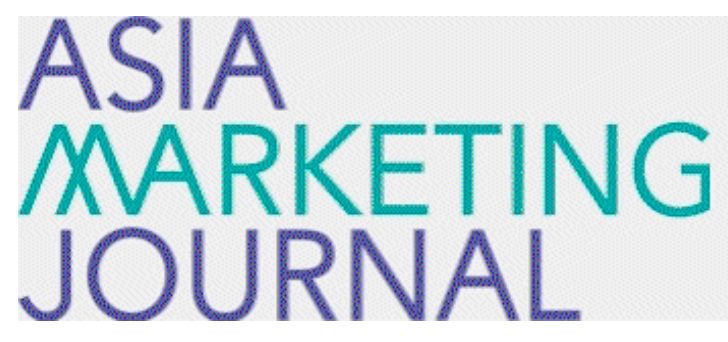

ASIA MARKETING JOURNAL

Volume 16 | Issue 4

Article 2

$1-31-2015$

\title{
The Effect of Congruency and Familiarity of Background Music in TV Advertising on the Music's Role as a Retrieval Cue
}

Insuk Hwang

Hwa-Kyung Kim

Follow this and additional works at: https://amj.kma.re.kr/journal

Part of the Marketing Commons

\section{Recommended Citation}

Hwang, Insuk and Kim, Hwa-Kyung (2015) "The Effect of Congruency and Familiarity of Background Music in TV Advertising on the Music's Role as a Retrieval Cue," Asia Marketing Journal: Vol. 16 : Iss. 4 , Article 2.

Available at: https://doi.org/10.15830/amj.2015.16.4.1

This Article is brought to you for free and open access by Asia Marketing Journal. It has been accepted for inclusion in Asia Marketing Journal by an authorized editor of Asia Marketing Journal. 


\title{
The Effect of Congruency and Familiarity of Background Music in TV Advertising on the Music's Role as a Retrieval Cue
}

\author{
Insuk Hwang* \\ Hwa-Kyung Kim**
}

\begin{abstract}
Assuming that not all background music in advertising function as effective retrieval cues for the advertised messages, this study proposes that we should be able to distinguish the retrieval cue effect of music from the simple ad exposure effect. This study tries to identify which specific characteristics of music are related to the retrieval cue effect. Our experiment focuses on congruency and familiarity of music as key characteristics of music which affect the effectiveness of the music's role as a retrieval cue for the advertised messages.
\end{abstract}

We used four groups of subjects to test the retrieval cue effect of the background music. Each group was exposed to one of the four different types of background music and was again sub-divided into an experimental and a control group (i.e., a total of eight independent sub-groups were included in the experiment.) The first two sub-groups were exposed to the experimental advertisement with the background music of high congruency and high familiarity. After the ad exposure, the background music was provided as a retrieval cue to only one of the two sub-groups. Comparison of the memory performance between the two sub-groups will reveal the net retrieval cue effect of the music of high congruency and high familiarity. Similarly, another two sub-groups watched the same ad but with the background music of high congruency and low familiarity. Also the same ad but with the music of low congruency/ high familiarity was shown to another two sub-groups and that of low congruency and low familiarity music was to another two. Among the two sub-groups with the same music, only one group had the music cue at the memory tasks. One hundred and seventy four undergraduate students at the college of one of authors in Asia participated in the study. Their ages ranged from 18 to 24 with a median of 20 . The sample was composed of 51.7 percent male subjects. They were randomly assigned to each of the eight sub-group.

\footnotetext{
* Professor, Department of Business Administration, University of Seoul(hwangis@uos.ac.kr), First Author

** Professor, Department of Hotel Management, Jeju International University(agnes1101@hanmail.net), Corresponding Author
} 
The results show that the music highly congruent with the advertised message facilitates the message retrieval, while the low congruency music cue does not. It was also found that the low familiarity music cue improves memory performance only when the music is perceived as congruent with the advertised message.

From a theoretical and practical perspective, this study provides boundary conditions for effective retrieval and suggests that the congruent music specifically created for the ad is a more effective retrieval cue than other types of music cues.

Key words: Background Music, A Retrieval Cue, Congruency, Familiarity

\section{Introduction}

There have been many studies on the effect of background music in advertising. Some of them focused on how consumers responded emotionally to advertising music and how the emotional responses enhanced the advertising effect (e.g., Alpert, Alpert, and Maltz 2005; Bruner II 1990; MacInnis and Park 1991). Others have investigated how consumers re- $^{-}$ sponded cognitively to the advertising music (e.g., Allan 2006; Hahn and Hwang 1999; Maher, Hu, and Kolbe 2006; Roehm 2001).

This study focuses on another potentially important role of music in advertisements: the music's role as a retrieval cue for the advertised message. Facilitating the recall or the recognition of the advertising messages in offline stores or in the Internet (or infomercial) advertising where a specific product is being re-advertised and the purchase is made, is very important. The advertising music will en- hance the likelihood of consumers' remembering and thus purchasing the brand. If the music used in the advertising can be an effective retrieval cue for advertising messages stored in consumers' long-term memory, playing the advertising music in the stores can be an effective way to improve the sales of the advertised brand.

Few studies have explored the role of music as a retrieval cue in ads (Stewart, Farmer, and Stannard 1990; Tom 1990). These studies reveal limitations in two important aspects. First, they failed to differentiate the retrieval cue effect of music from the effect of simple ad exposure. Apparently, the effect of ad exposure, (A) in Figure 1, is related to consumers' memory performance without any external aids (i.e., retrieval cues). The memory performance is only affected by advertising itself or the individual factors such as information processing ability and/or involvement. Meanwhile the retrieval cue effect of music, (C) in Figure 1, can be conceptualized as the difference be- 
〈Figure 1〉 A Conceptualization of Retrieval Cue Effect of Background Music in Ads

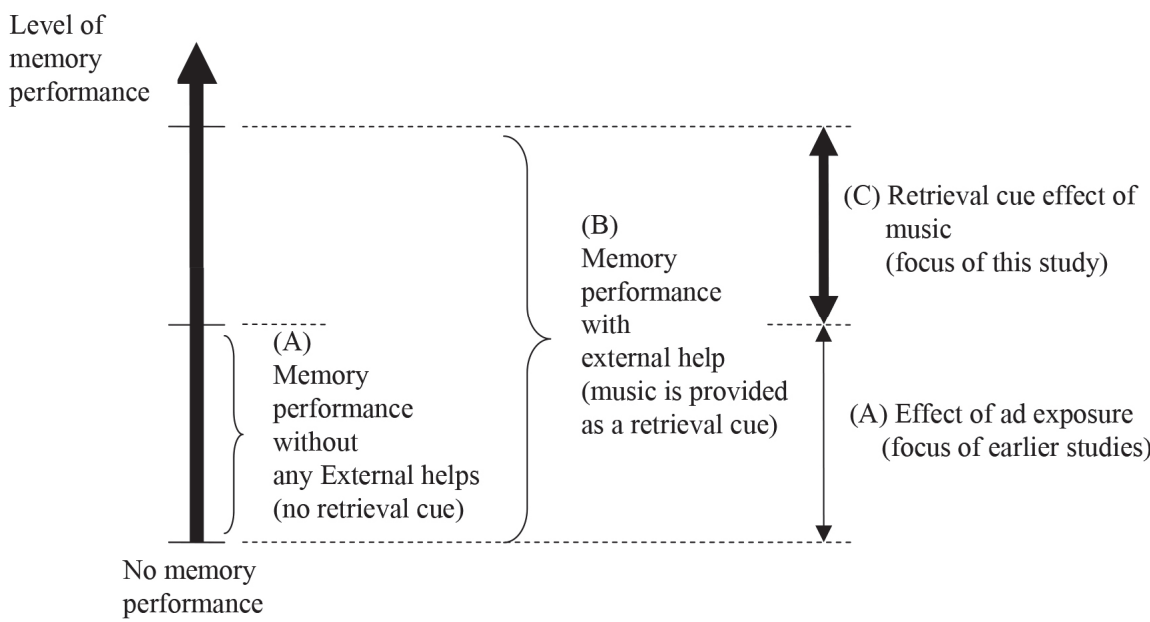

tween the memory performance with and without a musical retrieval cue (that is, the difference between (B) and (A) in Figure 1). The current research will empirically investigate the effect of music as a retrieval cue in TV ad context by comparing the memory performance with and without the musical cue. The retrieval cue effect of music is the main focus in this study while the effect of ad exposure has been the focus of earlier studies (e.g. Allan 2006; Kellaris, Cox, and Cox 1993; Maher, Hu, and Kolbe 2006).

Second, past research has implicitly assumed that the use of music as a retrieval cue always enhances recall and recognition of ad messages without specifying the characteristics of music related to the retrieval cue effect. While music possesses some properties that influence the ad message processing (Kellaris et al. 1993), not all background music in ads function equally well as retrieval cues. Based on the previous studies, this study proposes that two characteristics of music are closely related to the re- $^{-}$ trieval cue effect: the music's familiarity and its congruency with the advertised message.

\section{Literature Review}

\subsection{The Effect of Retrieval Cues}

Retrieval cues can play a critical role in helping consumers retrieve the ad information stored in their long-term memory. Most of the research about the retrieval cues investigated the memory performance when a word such as a brand name or a category name was presented as a retrieval cue (e.g. Alba and Hutchinson 1987; Bellezza and Hartwell 1981; Lindsey and 
Krishnan 2007; Nedungadi et al. 2001). Some of them showed that a verbal cue could facilitate consumers' memory performance. While the facilitative effect of verbal cues was observed when there were direct associations between a retrieval cue and information stored in the long-term memory, the same effect was not observed when the associations were weak (e.g. Hudson and Davis 1972; Rundus 1973). According to the Associated Network Model, the association refers to the link between the retrieval cue and the information to be retrieved from the long-term memory (Anderson, 1990). If there is a strong association between the retrieval cue and the information to be retrieved, a strong link will be formed between the two informational nodes (the music and the ad information) in consumers' memory, and the retrieval cue will help retrieve the target information effectively. On the other hand, if there is no strong association between the retrieval cue and the information to be retrieved, no clear link will be formed between them in the long-term memory, and the cue may not effectively help the retrieval of target information (i.e., Keller 1987). From the theoretical perspective, if there is no clear link between the music and the target information, the music will have little influence on the recall of the target information.

\subsection{The Visual and Auditory Retrieval Cues}

Consumers have many opportunities to be exposed to the visual retrieval cues such as photographs of the advertising models printed on the packages of the products in the real purchase situations. Also, stores may use ad music as an auditory retrieval cue for advertisements. However, compared to studies of verbal retrieval cues, there have been few studies on the effects of visual or auditory retrieval cues.

Keller (1987) reported that showing a photograph taken from the advertisement was shown on the package of the product facilitated the memory performance of consumers. The result implies that a visual cue at the point of purchase can help consumers retrieve the ad information stored in their memory. In another study, Macklin (1994), using young children as participants, also showed that memory performance for television advertising was improved by providing a visual cue. However, in her study, the positive result of a visual retrieval cue appeared only when the children were exposed three times to the test advertisement.

To date, two studies have focused on the role of music as a retrieval cue in an ad context. Stewart, Farmer, and Stannard (1990) compared the effectiveness of a music cue with that of a verbal cue such as a brand name. They found that ad awareness increased by $61 \%$ in one month from the start of a campaign, by $80 \%$ 
in two months, and by more that $90 \%$ in six months when given a musical cue. In their study, the facilitating effect of a musical cue on ad awareness was larger than a verbal cue (58\%, 60\%, and 66\%, respectively). The authors claim that these results support the superior sensitivity of the musical cue. Tom (1990) compared a number of original songs, the parodies of hit music (rewriting the words of hit music), and the hit music in their facilitative effects on ad messages recall. The results of the study indicate that the music composed for the specific advertised brand is a more effective retrieval cue than the other types of music cues, such as parodies of hit music, which in turn are more effective than the original hits. These studies suggest that ad music may play a role of an effective retrieval cue. However, the works by Stewart et al. (1990) and Tom (1990) have some limitations as described earlier. Furthermore, they did not consider such factors as ad exposure frequency, prior ad involvement, and prior ad evaluation. Their research, as such, cannot provide clear-cut explanation about the net retrieval cue effect of ad music.

\subsection{The Effects of Congruency and Familiarity of Music on Memory Performance}

Several studies have investigated the effects of congruency and familiarity of music on memory performance. Those effects refer to the part represented as (A) but not as (C) in Figure 1. Kellaris et al. (1993) defined congruency of music as the extent to which purely instrumental music evokes meanings (i.e., thoughts, images, feelings) that are congruent with those evoked by ad messages. They found that congruent music enhanced memory performance compared to incongruent music only under a high attention condition. Similarly, Oakes (2007) found that increased musical congruity or musical fit with the ad contributed to the enhanced recall facilitation.

Regarding familiarity of music, Hilliard and Tolin (1979) found that familiarity with background music also enhanced reading comprehension. Similarly, Hahn and Hwang (1999) found that high familiarity music increased message recall more than low familiarity music in TV advertising. In their second study, however, familiarity of music in TV ads did not affect memory performance. Therefore, further research is needed for a clear understanding of the effects of familiarity with background music in ads on memory performance.

\section{Hypotheses}

As noted earlier, if there is a strong semantic association between a retrieval cue and the target information, a clear and strong link between them will be formed in the long-term memory. As a result, the cue may effectively 
help retrieving the target information whenever it is needed. In contrast, if the association is weak, there will be no (or very weak) clear link between them in the long-term memory and the retrieval cue will not lead to effective information retrieval.

Then what characteristics of music would be related to the strong association with ad messages? This study proposes that the congruency between the music and the ad messages serve as one of the possible characteristic. The congruency has been originally proposed by Kellaris et al. (1993), who stress the congruency between meanings evoked by purely instrumental music and those by ad messages. It can be inferred that a highly congruent music will be effective in retrieving the ad messages because there exists a clear link between the music and the ad messages in the long-term memory. A less congruent music, on the contrary, will not function as an effective retrieval cue because there is no clear link between them in the long-term memory. Based on this reasoning, the hypothesis is proposed to test the retrieval cue effect of music in a TV ad context.

H1: A high congruency music will generate a more positive retrieval cue effect than a low congruency music.

The uniqueness of a link between a retrieval cue and the target information in the longterm memory is also expected to have a pos- itive effect on retrieving target information (e.g., Burke and Srull, 1988; Thelen and Woodside, 1997). For example, Figure 2 shows that the uniqueness of the link between the retrieval cue and the target information is higher in (b) than in (a). In each case, when a retrieval cue is provided for the retrieval of target information, it will be retrieved better in (b) than in (a). The retrieval of target information under the high uniqueness condition will be less influenced by the interference of the other information associated with the target information, compared to that in the low uniqueness condition in Figure 2-(a). In this regard, this study considers the uniqueness of link in the long-term memory as another factor that influences the retrieval cue effect.

What characteristic of music, then, is related to the uniqueness of a link between music and ad messages? This study suggests that the familiarity of background music in the advertisement will determine the uniqueness of the link in the long-term memory. The link between a familiar music and the ad messages in longterm memory will not unique because the music is expected to have many other links already with other pieces of information (i.e., information A, B and C in Figure 3 (a)). In contrast, the link between unfamiliar music and the ad messages will be unique because the music is not expected to have many other links in the long-term memory (Figure $3(\mathrm{~b})$ ). Therefore, unfamiliar music will serve as a 
〈Figure 2〉 The Uniqueness of a Link between the Retrieval Cue and the Target Information

\section{Long-term memory}

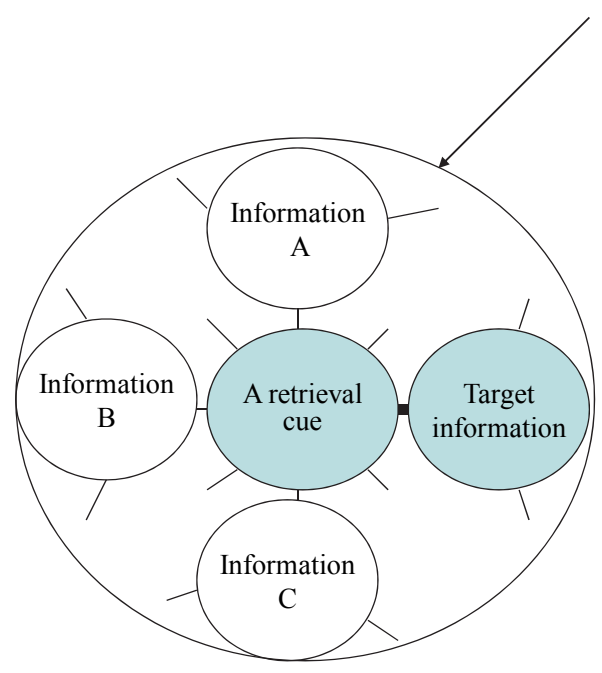

(a) Low uniqueness

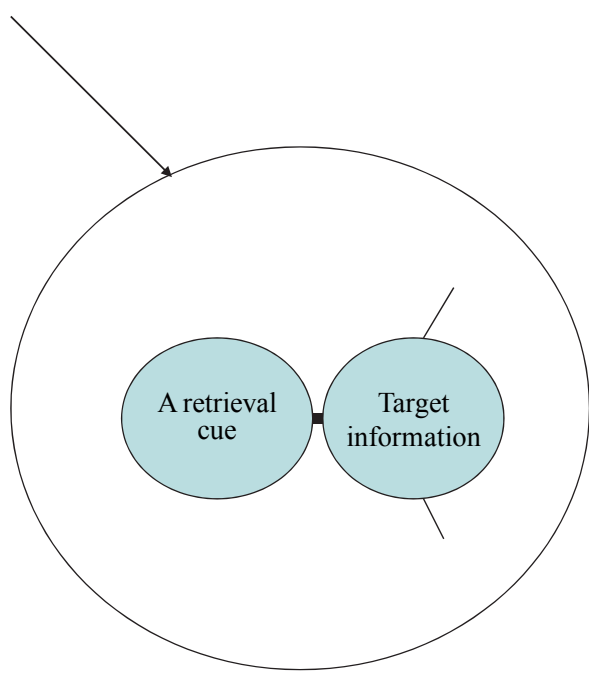

(b) High uniqueness

〈Figure 3〉 The Uniqueness of Familiar and Unfamiliar Music in Long-Term Memory

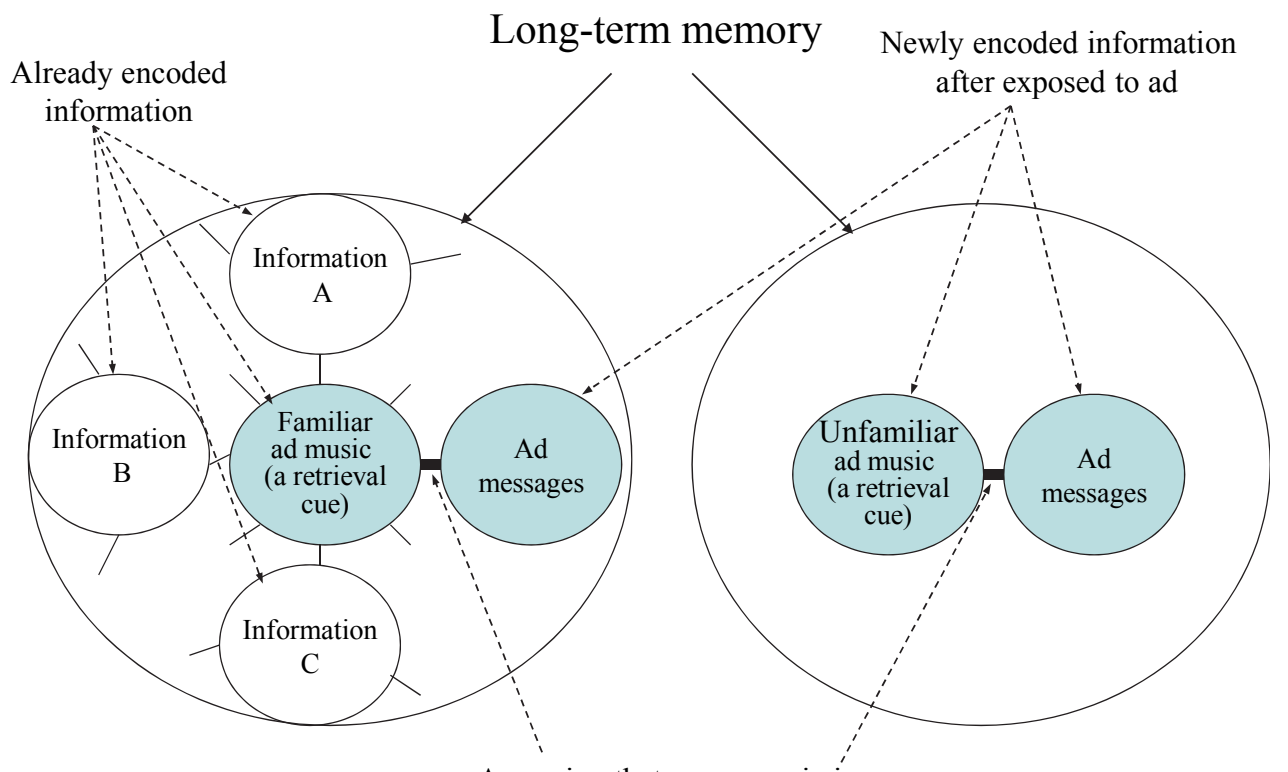

Assuming that every music is highly congruent with ad messages

(a) Familiar music's low uniqueness

(b) Unfamiliar music's high uniqueness

The Effect of Congruency and Familiarity of Background Music in TV Advertising on the Music's Role as a Retrieval Cue 7 
more effective retrieval cue than familiar music, because the ad messages under the high uniqueness condition will not be related to any other information that can give rise to confusion in memory retrieval process.

In order for the uniqueness of the link to increase the retrieval of the ad messages, a clear link between the music and the ad messages should exist. The familiarity of ad music affects the memory performance via the congruency between the music and the ad messages. More specifically, it is only when the music is highly congruent with ad messages that the uniqueness of the music has its effects on memory performance. Based on this notion, the following hypothesis is proposed:

H2: Unfamiliar music will be more effective in creating a positive retrieval cue effect than familiar music, only when the music is congruent with the ad messages.

\section{Method}

\subsection{Experimental Design and Stimuli}

We used four groups of subjects to test the retrieval cue effect of the background music. Each group was exposed to one of the four different types of background music and was again sub-divided into an experimental and a control group (i.e., a total of eight independent sub-groups were included in the experiment.) The first two sub-groups were exposed to the experimental advertisement with the background music of high congruency and high familiarity. After the ad exposure, the background music was provided as a retrieval cue to only one of the two sub-groups. Comparison of the memory performance between the two sub-groups will reveal the net retrieval cue effect of the music of high congruency and high familiarity. Similarly, another two sub-groups watched the same ad but with the background music of high congruency and low familiarity. Also the same ad but with the music of low congruency/ high familiarity was shown to another two sub-groups and that of low congruency and low familiarity music was to another two. Among the two sub-groups with the same music, only one group had the music cue at the memory tasks. One hundred and seventy four undergraduate students at the college of one of authors in Asia participated in the study. Their ages ranged from 18 to 24 with a median of 20. The sample was composed of 51.7 percent male subjects. They were randomly assigned to each of the eight sub-group.

Four different versions of a 30-second TV ad were created for a fictitious soap named 'Lubins' by a professional producer of TV commercials. As noted, the ads were identical except for the background music. The volume, the sequence, and the duration of the music were constant 
for all the conditions. An announcer delivered the verbal commercial messages while the background music was playing. The verbal messages were as follows: "Lubins. It does not irritate your skin. It is a delicate soap with natural tenderness and aroma. It gives freshness to your skin. It comes to you with an ultimate sense of purity. Alkaline soap for you. Lubins." In the meantime, the brand name was also visually shown on a TV screen. The visual part of TV commercial featured a female endorser's face, her pure skin tone, and a romantic atmosphere.

\subsection{Pretest}

A pretest was conducted to select the appropriate music for each condition. Based on our subjective judgment, twenty classical musical pieces were selected as the candidates for the study.

An independent sample of forty undergraduate students was asked to listen to each of the thirty-second musical excerpts one by one through a cassette player and rated each in terms of familiarity and likeability. Following that, they also rated the level of congruency between the music and each of the target brand attributes used in the main experiment ("does not irritate," "delicate," "natural," "tenderness," "aroma," "freshness," and "sense of purity"). They listened to each excerpt twice through a cassette player since they found it difficult to rate the congruency. Items measuring familiarity, likeability, and congruency were the same as those used in the main experiment and are described in the Other Variables and Manipulation Check sections.

Based on the pretest, excerpts from W. A. Mozart's Symphony No.1 KV 16 1mvt. (low congruency, 3.70; low familiarity, 3.80), L. V. Beethoven's Symphony No.5 op 67 1mvt. (low congruency, 2.90; high familiarity, 6.15), A. Vivaldi's Concerto for Flute and String Orchestra D-major Op.10 No.3 2mvt (high congruency, 5.14; low familiarity, 3.98), and W. A. Mozart's Concerto No. 21 for Piano and Orchestra KV 467 2mvt. (high congruency, 5.53; high familiarity, 5.91) were selected for the main experiment. The rated scores of the musical excerpts rated low on the congruency or familiarity dimension were significantly different from those rated high (all p-values $<.01$ ). The scores of likeability for each musical piece ranged from 4.2 to 5.1. It should be noted that responses to music (i.e. thoughts, feelings, familiarity) may vary across countries, especially between Eastern and Western countries.

\subsection{Procedure}

The experiment took place at a regular undergraduate class time. Before the experiment, all participants were told that the purpose of the study was to analyze consumers' responses to a TV program. As a cluster, a thirty-second 
target ad and a filler ad were shown three times: at the beginning, the middle, and the end of the thirty-minute program, "America's Funniest Home Videos." The program had not been on air in the country where the study was carried out. The filler ad was for an automobile which were actually broadcast in some other countries one year before the main $\mathrm{ex}^{-}$ periment was carried out. It was found that no participants had watched the filler ad before the experiment.

After watching the program and the ads, the participants in each experimental condition took a distraction task of answering several questions about the TV program before performing the recall and the recognition tests. The recognition task was done after the recall task. The participants were given four minutes for the recall and recognition tasks, two minutes per each task.

After the memory tasks, participants filled out items measuring the likeability and familiarity of the background music and the congruency between music and ad messages. At the end of the experiment, all participants were given a debriefing questionnaire asking them to report what they believed to be the purpose of the study. The entire experimental procedure took about one hour.

\subsection{Dependent Variables}

Open-ended questions were used to measure unaided brand name recall and attribute-message recall. To measure the unaided recall of the brand name, participants were asked, "Was there a specific brand name of the soap mentioned in the ad? If so, what was it?" The attribute-message recall was prompted by the questions, "What are the important points the advertised messages? Please list as many messages as you can remember. What other details do you remember from the advertisement?" These measures were patterned after those used in previous recall studies (e.g. Nedungadi et al. 2001). Brand name recall was scored as one if it was identical or phonetically similar to the actual brand name; otherwise, it was scored zero. Attribute message recall was calculated based on the written protocol of the brand's attribute messages ("does not irritate," "delicate," "natural," "tenderness," "aroma," "freshness," and "sense of purity") (Bettman and Park, 1980; Lee, 2000). Four graduate students without any knowledge of the study purposes evaluated the message recall scores independently. A comparison of their judgments showed a 97\% agreement. The recall score was the sum of the brand name recall and the attribute message recall scores because few participants had recalled the brand name (none or only one in each condition).

In addition to the unaided recall, we measured recognition. Brand and attribute message recognition were measured by the checklist which contained filler items, as used by Shapiro and 
Krishnan (2001). The brand name and attribute messages were embedded in a 21-item checklist. Participants were given 1 point for each correctly recognized item.

\subsection{Other Variables}

After performing the recall and recognition tasks, participants answered questions about items measuring likeability and the level of attention given to background music. While responding to these items, the participants repeatedly heard background music. Three seven-point scale items were used to measure the likeability of music, indicating the extent to which the music they heard was good, pleasant, or liked $(a=.91)$. Afterwards, participants were asked to indicate how much attention they had paid to the background music when exposed to the TV ads on a seven-point scale (1=paid no attention at all, $7=$ paid exclusive attention) (Park and Young, 1986). For further analysis, all multi-item scales were averaged. The scores of likeability for each music ranged from 4.3 to 4.9 and those of level of attention from 3.0 to 3.3 .

\subsection{Manipulation Check}

Manipulation checks for congruency and familiarity were performed. The level of congruency of background music with ad messages was measured with three seven-point scale items (congruent, harmonious, matched; $a=.87$ ). For example, one of these items was as follows: "the meanings, images, or emotions of the music are well matched with the phrases or words such as 'does not irritate,' 'delicate,' 'natural,' 'tenderness,' 'aroma,' 'freshness,' and 'sense of purity' ( $1=$ strongly disagree, $7=$ strongly agree)."

The familiarity of music was measured by three seven-point scale items (be familiar with the music, have heard the music many times, and be well-acquainted with the music; $a=$ .87). For example, participants were asked to indicate how familiar they felt with the music they had heard ( $1=$ not familiar at all, $7=$ very familiar). Participants heard the background music through a cassette player while responding to these items. At the end of the experiment, the participants were asked to fill out an open-ended question to check if they guessed research hypotheses correctly. Two judges independently coded participants' responses and their judgments showed 100 percent agreement.

\section{Results}

\subsection{Checks for Hypothesis Guessing and Manipulation}

An analysis of the response to the hypothesis guessing question revealed that two partic- 
ipants correctly guessed the study hypotheses, whose data were excluded from further analyses. Manipulation checks for the congruency and familiarity measures were carried out using ANOVA. The low congruent and low familiar music had a congruency score of 3.53 and a familiarity score of 4.01. The scores were 2.64 and 6.37 for the low congruent and high familiar music, 4.85 and 4.29 for the high congruent and low familiar music, and 5.34 and 5.71 for the high congruent and high familiar music, respectively. The results indicate that the manipulations of congruency and familiarity were successful $(\mathrm{F}=111.98, \mathrm{p}<.001 ; \mathrm{F}=94.90, \mathrm{p}$ $<.001$, respectively). The two constructs were not correlated (Pearson's $a=.01 ;$ N.S.)

\subsection{Hypothesis Testing}

To examine the retrieval cue effect of music, the memory scores between conditions with and without music cue were compared. In order to test H1, one-way ANOVA was used between conditions with and without the musical cue under high congruency condition. As a result, the mean recall scores with the cue was significantly higher than that of no cue condition (.92 vs. 1.97, $\mathrm{F}=8.99, \mathrm{p}<.01$, Table 1). Similarly, the significant difference between the recognition means was also found (1.55 vs. $2.30, \mathrm{~F}=6.87, \mathrm{p}<.01$, Table 1$)$. However, there was no significant difference in both of the memory measures between cue and no cue conditions under low congruency (recall, .78 vs. .80, $\mathrm{F}=.00$, N.S.; recognition, 1.46 vs. $1.18, F=1.17$, N.S., Table 1). These results support $\mathrm{H} 1$ indicating that the high congruency between music and ad messages improves the recall and recognition of the ad messages. If there is no music-message congruency, the musical cue will not be effective in facilitating the message retrieval. This study makes a contribution to our understanding of the characteristics of background music related to its retrieval cue effect.

$\mathrm{H} 2$ asserts the interaction of the familiarity

〈Table 1〉 Recall and Recognition Scores by Conditions of Music Congruency

\begin{tabular}{|c|c|c|c|c|}
\hline \multirow[b]{2}{*}{$\begin{array}{l}\text { Music } \\
\text { condition }\end{array}$} & \multirow[b]{2}{*}{$\begin{array}{l}\text { Memory } \\
\text { measures }\end{array}$} & \multicolumn{2}{|c|}{ Retrieval cue condition } & \multirow[b]{2}{*}{$\begin{array}{l}\text { Retrieval cue effect } \\
\text { of music }((B)-(A))\end{array}$} \\
\hline & & $\begin{array}{l}\text { No music cue } \\
(\mathrm{A})\end{array}$ & $\begin{array}{l}\text { Music cue } \\
\text { (B) }\end{array}$ & \\
\hline \multirow{2}{*}{$\begin{array}{c}\text { High } \\
\text { congruency }\end{array}$} & Recall & .92 & 1.97 & $\Delta 1.05(\mathrm{~F}=8.99)^{* *}$ \\
\hline & Recognition & 1.55 & 2.30 & $\Delta .75(\mathrm{~F}=6.87)^{* * *}$ \\
\hline \multirow{2}{*}{$\begin{array}{c}\text { Low } \\
\text { congruency }\end{array}$} & Recall & .78 & .80 & $\Delta .02(\mathrm{~F}=.00)$ \\
\hline & Recognition & 1.46 & 1.18 & $-\Delta .28(\mathrm{~F}=1.17)$ \\
\hline
\end{tabular}

\footnotetext{
Note: The background music used in each music condition served as a retrieval cue in the corresponding music cue condition.

$* * \mathrm{p}<.01$
} 
and the congruency implying that an unfamiliar music will be more effective in helping the memory retrieval than a familiar music, only when the music is congruent. For the test of H2, this study used the method of parallelism testing (Kleinbaum, Kupper, and Muller, 1988). The method tests whether the retrieval cue effect in high congruency and low familiarity condition is significantly higher than that in high congruency and high familiarity condition. Results showed that there was a significant difference in the recall task ( $\Delta 1.21$ vs. $\Delta .86$, $t=3.19, p<.01$, Table 2) as well as in the recognition task $(\Delta 1.20$ vs. $\Delta .25, \mathrm{t}=3.62, \mathrm{p}<.001$, Table 2). When the music is incongruent with the ad messages, there was no significant difference in both of the memory measures between the low and the high familiarity conditions (recall, $\Delta .15$ vs. $-\Delta .03, t=1.50$, N.S.; recognition, $-\Delta .33$ vS. $-\Delta .11, t=1.52, \quad$ N.S., Table 2). Therefore, H2 is also supported. This implies that care must be taken for the familiarity of music in order to utilize music strategically in increasing message memory in a communication context.

\section{Discussion}

This study attempts to investigate what characteristics of music facilitate message retrieval, based on the speculation that not all music is effective as a retrieval cue. It was found that the congruency of music, as proposed by this study, produced the retrieval cue effect. Specifically, the message retrieval was improved when background music congruent

〈Table 2〉 Recall and Recognition Scores by Conditions of Music Congruency and Familiarity

\begin{tabular}{|c|c|c|c|c|c|}
\hline \multirow{2}{*}{\multicolumn{2}{|c|}{$\begin{array}{c}\text { Music } \\
\text { condition }\end{array}$}} & \multirow{3}{*}{$\begin{array}{c}\text { Memory } \\
\text { measures }\end{array}$} & \multicolumn{2}{|c|}{ Retrieval cue condition } & \multirow[b]{2}{*}{$\begin{array}{l}\text { Retrieval cue effect } \\
\text { of music }((B)-(A))\end{array}$} \\
\hline & & & $\begin{array}{l}\text { No music cue } \\
(\mathrm{A})\end{array}$ & $\begin{array}{l}\text { Music cue } \\
\text { (B) }\end{array}$ & \\
\hline \multirow{4}{*}{$\begin{array}{c}\text { High } \\
\text { congruency }\end{array}$} & \multirow{2}{*}{$\begin{array}{c}\text { High } \\
\text { familiarity }\end{array}$} & & 1.25 & 2.11 & $\Delta .86(\mathrm{~F}=4.00)^{*}$ \\
\hline & & Recognition & 1.92 & 2.17 & $\Delta .25(\mathrm{~F}=.40)$ \\
\hline & \multirow{2}{*}{$\begin{array}{c}\text { Low } \\
\text { familiarity }\end{array}$} & Recall & .63 & 1.84 & $\Delta 1.21(\mathrm{~F}=4.98)^{*}$ \\
\hline & & Recognition & 1.22 & 2.42 & $\Delta 1.20(\mathrm{~F}=8.89)^{* *}$ \\
\hline \multirow{4}{*}{$\begin{array}{l}\text { Low } \\
\text { congruency }\end{array}$} & \multirow{2}{*}{$\begin{array}{c}\text { High } \\
\text { familiarity }\end{array}$} & Recall & .91 & .88 & $-\Delta .03(\mathrm{~F}=.02)$ \\
\hline & & Recognition & 1.61 & 1.50 & $-\Delta .11(\mathrm{~F}=.09)$ \\
\hline & \multirow{2}{*}{$\begin{array}{c}\text { Low } \\
\text { familiarity }\end{array}$} & Recall & .57 & .72 & $\Delta .15(\mathrm{~F}=.26)$ \\
\hline & & Recognition & 1.21 & .88 & $-\Delta .33(F=.90)$ \\
\hline
\end{tabular}

Note: The background music used in each music condition served as a retrieval cue in the corresponding music cue condition.

$* * \mathrm{p}<.01, * \mathrm{p}<.05$ 
with ad messages was provided as a retrieval cue. This finding contributes to the existing theory of marketing communication and advertising in several ways. First, from a theoretical perspective, this study provides boundary conditions for effective retrieval. This study asserts that the congruency of background music with ad messages influences memory performance. This indicates that providing music as a retrieval cue is not sufficient to increase ad message retrieval. When selecting background music, marketers need to consider the congruency between music and ad messages in order to facilitate consumers' memory performance. Second, findings from the study provide valuable insights for decision making in current marketing environments. When choosing background music for TV or radio commercials, practitioners should seriously consider the congruency or relevance of music with ad messages. Adopting popular music does not necessarily improve ad message retrieval. Advertisers should carefully select music in terms of its congruency with product images, product attributes, and so on. When congruent background music is provided in a purchase situation, it may facilitate ad message retrieval and eventually lead to a sales increase.

Another important property of music suggested in this study is familiarity (i.e., uniqueness). The result suggests that congruent but less familiar music is more effective as a retrieval cue than both congruent and familiar music. The finding indicates that the unique association between unfamiliar music and ad messages facilitates the retrieval of messages. This comes from the fact that familiar music is linked to many other informational nodes, which results in more memory interference. Therefore, according to the results, the best way to achieve the retrieval effect of music is to create commercial music that provides a unique link with the product. This finding is in line with the previous empirical results (e.g. Tom 1990) that suggest the music specifically created for the ad is a more effective retrieval cue than other types of music cues. However, in this case, it should be recognized that the effective retrieval of messages is due to its firm encoding in the long-term memory.

The study has some limitations. First of all, this study used only one product in examining the effects of music in TV commercials. It will be necessary to include more products and background music in order to investigate the extent to which congruency and familiarity influence memory performance in a substantive manner.

Second, being performed in a restricted situation, the study would have another limitation of external validity. Note that, in real situation, the environment of ad exposure is very noisy and the audience does not pay attention to the ad in general. Third, future investigation should examine other characteristics of music that can have a potential influence on memory performance. 
Although this study focuses on only two characteristics of music, there can be many other characteristics related to the retrieval cue effect. For example, the congruency of consumers' mood (feeling) and the background music may also influence the message retrieval. Therefore, in order to better understand music as a true source for the retrieval cue effect, future research should explore the effect of other characteristics of music.

Background music is one of the important decision problems in advertising and marketing contexts. In spite of its practical importance, effects of music are not fully understood. In this regard, the investigation of the joint effect of congruency and familiarity in the study is expected to make an important contribution to the understanding of the effects of music in advertising and marketing contexts.

〈Received August 22. 2014〉

〈Accepted December 12. 2014〉

\section{References}

Allen, Chris and Thomas J. Madden (1985), "A Closer Look at Classical Conditioning," Journal of Consumer Research, 12(Dec.), 301-315.

Allan, D. (2006), "Effects of popular music in advertising on attention and memory," Journal of Advertising Research, 46, 434-
444.

Anand, P. and B. Sternthal (1990), "Ease of Message Processing as a Moderator of Repetition Effects in Advertising," Journal of Marketing Research, 27, 345-353.

Baker, J., A. Parasuraman, D. Grewal, and G. B. Voss (2002), "The Influence of Multiple Store Environment Cues on Perceived Merchandise Value and Patronage Intentions," Journal of Marketing, 66(April), 120-141.

Batra, R. and Ray, M. (1983), “Advertising Situations: The Implications of Differential Involvement and Accompanying Affect Responses," in Information Processing Research in Advertising, R. Harris, eds, New York: Erlbaum, 127-151.

Bruner II, G. C. (1990), "Music, Mood, and Marketing," Journal of Marketing, 54(4), 94-103.

Caldwell, C. and S. A. Hibbert (2002), "The Influence of Music Tempo and Musical Preference on Restaurant Patrons' Behavior," Psychology and Marketing, 19(11), 895917.

Dawson, Scott, Peter H. Bloch, and Nancy M. Ridgway (1990), "Shopping Motives, Emotional States, and Retail Outcomes," Journal of Retailing, 66 (Winter), 408-427.

Donovan, R. J. and J. R. Rossiter (1982), “Store Atmosphere: An Environmental Psychology, Journal of Retailing, 58, 34-57.

Dunbar, David S. (1990), "Music, and Advertising," International Journal of Advertising, 
9(3), 197-203.

Eroglu, Sevgin A., Karen A. Machleit, and Jean-Charles Chebat, "The Interaction of Retail Density and Music Tempo: Effects on Shopper Responses," Psychology and Marketing, 22(7), 577-589.

Dube, L. and S. Morin (2001), "Background Music Pleasure and Store Evaluation: Intensity Effects and Psychological $\mathrm{Me}^{-}$ chanisms," Journal of Business Research, 54(2), 107-114.

Dube, L., Jean-Charles Chebat and S. Morin (1995), "The Effects of Background Music on Consumers Desire to Affiliate in BuyerSeller Interactions," Psychology and Marketing, 12(4), 305-319.

Goldsmith, Ronald E. and Barbara Lafferty (2000), “The Impact of Corporate Credibility and Celebrity Credibility on Consumer Reaction to Advertisements and Brands," Journal of Advertising, 29(3), 44-54.

Gorn, G. J. (1982), "The Effects of Music in Advertising on Choice Behavior: A Classical Conditioning Approach," Journal of Marketing, 46(1), 94-101.

Gorn, G.J., M. E. Goldberg, A. Chattopadhyay, and D. Litvack, (1991), "Music and Information in Commercials: Their Effects with an Elderly Sample," Journal of Advertising Research, 31(5), 23-32.

Hahn, Minhi and Insuk Hwang (1999), "Effects of Tempo and Familiarity of Background Music on Message Processing in TV Ad- vertising: A Resource Matching Perspective," Psychology and Marketing, 16(8), 659-676.

Herrington, J. D. (1996), "Effects of Music in Service Environments: A Field Study," The Journal of Services Marketing, 10(2), 26-41

Hilliard, O. M. and P. Tolin (1979), "Effects of Familiarity with Background Music on Performance of Simple and Difficult Reading Comprehension Tasks," Perceptual and Motor Skills, 49, 713-714.

Hoyer, W. D., R. K. Srivastava, and J. Jacoby (1984), "Source of Miscomprehension in Television Advertising," Journal of Advertising, 13(2), 17-26.

Kellaris, J. J., A.D. Cox, and D. Cox (1993), "The Effect of Background Music on Ad Processing: A Contingency Explanation," Journal of Marketing, 57(4), 114-125.

Kleinbaum, D. G., L. L. Kupper, and K. E. Muller (1988), Applied Regression Analysis and Other Multivariable Methods, PWSKENT: Wadsworth.

MacInnis, D. J. and C. W. Park (1991), "The Differential Role of Music on High- and Low-involvement Consumers' Processing of Ads," Journal of Consumer Research, 18(2), 161-173.

Maher, J. K., M. Y. Hu, and R. H. Kolbe (2006), “Children's recall of television ad elements- An examination of audiovisual effects," Journal of Advertising, 35(1), 23-33. 
McEwen, William J. and Clark Leavitt (1976), "A Way to Describe TV Commercials," Journal of Advertising Research, 16(6), 35-39.

Milliman, R. E. (1982), "Using Background Music to Affect the Behavior of Supermarket Shoppers," Journal of Marketing, 46(3), 86-91.

Milliman, R. E. (1986), "The Influence of Background Music on the Behavior of Restaurant Patrons," Journal of Consumer Research, 13(2), 286-289.

Oakes, S. (2007), "Evaluating empirical research into music in advertising: A congruity perspective," Journal of Advertising Research, 47, 38-50.

Park, C. Whan and S. M. Young (1986), "Consumer Response to Television Commercials: The Impact of Involvement and Background Music on Brand Attitude Formation," Journal of Marketing Research, 23 (Feb.), 11-24.

Petty, Richard E. and John T. Cacioppo (1985), "The Elaboration Likelihood Model of Persuasion," in Advances in Experimental Social Psychology, Vol.19, L. Berkowitz, ed. New York: Academic Press.

Petty, Richard E, John T. Cacioppo, and David Schumann (1983), "Central and Peripheral Routes to Advertising Effectiveness: The Moderating Role of Involvement," Journal of Consumer Research, 10(2), 135-146.

Pitt, Leyland F. and Russell Abratt (1988),
"Music in Advertisements for Unmentionable Products- A Classical Conditioning Experiment," International Journal of Advertising; Aug., 130-137.

Sewall, M. A. and D. Sarel (1986), "Characteristics of Radio Commercials and Their Recall Effectiveness," Journal of Marketing, 50(1), 52-60.

Stewart, D. W., K. M. Farmer, and C. I. Stannard (1990), "Music as a Recognition Cue in Advertising-Tracking Studies," Journal of Advertising Research, Aug/Sep, 39-48.

Stout, P. A., and J. D. Leckenby (1988), "Let the Music Play: Music as a Nonverbal Element in Television Commercials," in Nonverbal Communication in Advertising, S. Hecker and D. W. Stewart, eds., Lexington, MA: D.C. Heath., 207-223.

Till, B. D. and M. Busler (2000), "The MatchUp Hypotheses: Physical Attractiveness, Expertise, and the Role of Fit on Brand Attitude, Purchase Intention and Brand Beliefs," Journal of Advertising, 29(3), 1-13. Tom, G. (1990), "Marketing With Music," The Journal of Consumer Marketing, 7(2), 49-54.

Tulving, E., and D. M. Thomson (1973), "Encoding specificity and retrieval processes in episodic memory," Psychological Review, 80, 352-373.

Wallace, W. T. (1991), "Jingles in Advertisements: Can They Improve Recall ?," $A d^{-}$ 
vances in Consumer Research, 18, 239-242. Wind, Y. (1982), Product Policy: Concepts, Methods, and Strategy, Addison-Wesley Publishing Company.
Zaichkowsky, Judith L (1985), “Mesasuring the Involvement Construct," Journal of Advertising Research, 12(3), 341-352 